\title{
Rare species Iris scariosa and I. pumila in the Southern Urals
}

\author{
E.V. Mikhaylova ${ }^{1 *}$, A.N. Mustafina ${ }^{2}$, Y.M. Golovanov² ${ }^{2}$ A.V. Kryukova ${ }^{2}$ \\ ${ }^{1}$ Institute of Biochemistry and Genetics UFRC RAS, Ufa, Russia \\ ${ }^{2}$ South Ural Botanical Garden UFRC RAS, Ufa, Russia
}

DOI 10.18699/ICG-PlantGen2019-50

(c) Autors, 2019

* e-mail: mikhele@list.ru

\begin{abstract}
Iris scariosa and I. pumila are two rare species of Iris found in the steppes of the Southern Urals. Both of them are included in the Red Data Book of the Russian Federation. The Southern Urals is the area where these two species coexist. Therefore, it is important to study these unique populations, their morphological and genetic diversity and possibilities of hybridization. We studied DNA samples using different RAPD and ISSR primers and observed not only phenotypical, but also genetic interspecific and interpopulation variability between plants from 29 populations of irises discovered in the Southern Urals. Moreover, several samples distinguished as I. scariosa on the basis of external features, genetically showed higher similarity to I. pumila and might be hybrids.

Key words: Iris scariosa; Iris pumila; RAPD; ISSR.
\end{abstract}

\section{Introduction}

Iris scariosa and I. pumila are two rare species of Iris found in the steppes of the Southern Urals. Both of them are included in the Red Data Book of the Russian Federation. I. pumila is an ancestor of many modern cultivars, and I. scariosa is known for its drought and salt tolerance and can also be used in breeding. I. pumila is reported to have 30,31 , or 32 chromosomes, and I. scariosa has a chromosome count of $2 n=24$ (Randolph, Mitra, 1961) and rarely $2 n=40$. The Republic of Bashkortostan and Orenburg Oblast are situated on the eastern border of the I. pumila habitat and the western border of the I. scariosa habitat, so the Southern Urals is the area where these two species coexist. Both species demonstrate phenotypical variability on this territory (Kryukova et al., 2018). Therefore, it is important to study these unique populations, their morphological and genetic diversity and possibilities of hybridization. RAPD analysis was successfully used on Siberian and Far Eastern Iris species and allowed inter- and intraspecific polymorphism to be detected (Makarevitch et al., 2003). However, molecular analysis was never performed on Iris species in the Southern Urals. Here we present the first attempt to study the genetic diversity of I. pumila and I. scari$o s a$ in the area of their coexistence.

\section{Materials and methods}

The survey was carried out in the Southern Urals on the territory of Orenburg Oblast and the Republic of Bashkortostan. Leaves were collected from plants of Iris and dried in silica gel. DNA was extracted from these leaves using the salt method. RAPD primers OPD-08 (GTGTGCCCCA), OPD-11 (AGCGCCATTG), OPD-13 (GGGGTGACGA) and OPB-12 (CCTTGACGCA) were used according to Makarevitch et al. (2003). In addition, there were chosen universal RAPD primers AFK1 (ACGGTGGACG), OPC-06 (GAACGGACTC) and OPAI-05 (GTCGTAGCGG) and two ISSR primers 814 (СТСТСТСТСТCTCTCTTG) and IS3 (GAGAGAGAGAGAGAGAC).

PCR was performed in a $30-\mu l$ mixture including $5 \mathrm{U}$ TaqDNA polymerase, $3 \mu \mathrm{l}$ of 10x Taq buffer, $250 \mu \mathrm{M}$ dNTP, $5 \mathrm{mM} \mathrm{MgCl}_{2}, 20 \mathrm{pmol}$ of primer and iris DNA. RAPD analysis was carried out using the following protocol: initial denaturation at $94{ }^{\circ} \mathrm{C}$ for 3 min followed by 35 cycles of denaturation each for $50 \mathrm{sec}$ at $94{ }^{\circ} \mathrm{C}$, annealing for $1 \mathrm{~min} 10 \mathrm{sec}$ at $30{ }^{\circ} \mathrm{C}$, and elongation for $1 \mathrm{~min} 40 \mathrm{sec}$ at $72{ }^{\circ} \mathrm{C}$. The final elongation step was for $7 \mathrm{~min}$ at $72{ }^{\circ} \mathrm{C}$. ISSR analysis was carried out using the following protocol: initial denaturation for $5 \mathrm{~min}$ at $94^{\circ} \mathrm{C}$ followed by 35 cycles of denaturation each for $50 \mathrm{sec}$ at $94^{\circ} \mathrm{C}$, annealing for $50 \mathrm{sec}$ at $50^{\circ} \mathrm{C}$, and elongation for $1 \mathrm{~min} 50 \mathrm{sec}$ at $72^{\circ} \mathrm{C}$. The final elongation step was for $7 \mathrm{~min}$ at $72{ }^{\circ} \mathrm{C}$. Results were analyzed using ImageLab software.

\section{Results and discussion}

29 populations of Iris were discovered in Orenburg Oblast and the Republic of Bashkortostan (Figure 1). Plants from 15 populations were distinguished as I. pumila, and plants from 14 populations were distinguished as I. scariosa on the basis of morphological characteristics. Leaves were collected from 19 populations and used for DNA analysis.

Noteworthy, both species were detected at location 24. Closely located populations 13 and 20 as well as 11 and 21 could also be hybridization zones. Primers OPD08, OPD11, OPD13 and OPB12 gave stable, well-reproducible, speciesspecific patterns for the Siberian and Far Eastern Iris species with no variation between individuals (Makarevitch et al., 2003). However, these primers were not just as representative for I. pumila and I. scariosa. OPD-08, OPD-11 and OPD-13 gave a small number of bands, and OPB-12 gave good bands with some variation within populations (Figure 2). However, there were clear patterns for each species, and it can be seen from the electropherogram that both of them are present at location 25 (Figure $2(6,7)$ ) and the sample from location 24 (Figure 2 (5)) cannot be clearly associated with either of these patterns.

Bands specific for either I. pumila or I. scariosa were also detected with other ISSR and RAPD primers we used. The best results were obtained with ISSR primer 814 (Figure 3), which averagely produced 13 amplicons from I. scariosa DNA and 9 from I. pumila DNA. Six of them were present in both species, the others were polymorphic. In the populations that 


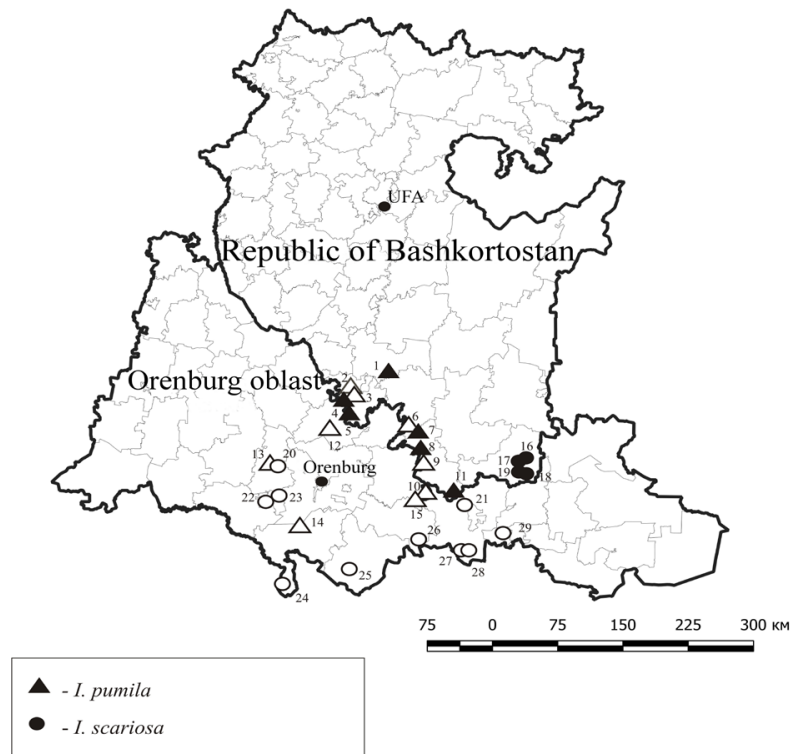

Figure 1. Location of the Iris populations studied (1-29) on the map of Orenburg Oblast and the Republic of Bashkortostan. Populations marked in white were chosen for DNA analysis.

were considered to be pure, variation between individuals was minimal.

Again, both patterns were present at location 25. Although plants from this population were distinguished as I. scariosa on the basis of morphological characteristics, some of them genetically were closer to I. pumila. They could either belong to this species or be hybrids. Bands specific for I. scariosa were detected in several samples from locations 13 and 14. The possibility of hybridization in these populations should also be considered. However, RAPD and ISSR are not accurate methods, though they can be used for primary screening of large numbers of samples. This approach has been successfully used to search for hybrids between Brassicaceae species several times (Mikhaylova, 2018). It may as well be applied to the species of Iris. However, our hypothesis must be confirmed by sequencing and chromosome analysis. After that our samples can also be compared with Siberian, Far Eastern and many other well studied Iris populations.

\section{Conclusions}

Both I. scariosa and I. pumila are reported to have unstable chromosome number, so the genetic diversity we observed in Southern Urals is understandable. Hybridization also can occur within the genus of Iris. I. pumila itself is considered to be a natural hybrid between I. pseudopumila and I. attica. Our investigation of unique populations of I. pumila and I. scariosa in the area of their coexistence in Southern Urals gave promising results. Hybrids between these species were never searched for and never found before. Such hybrids can be used in breeding of drought and salt tolerant cultivars of irises. Continuation of this research is important for the preservation of rare Iris species in the Southern Urals.

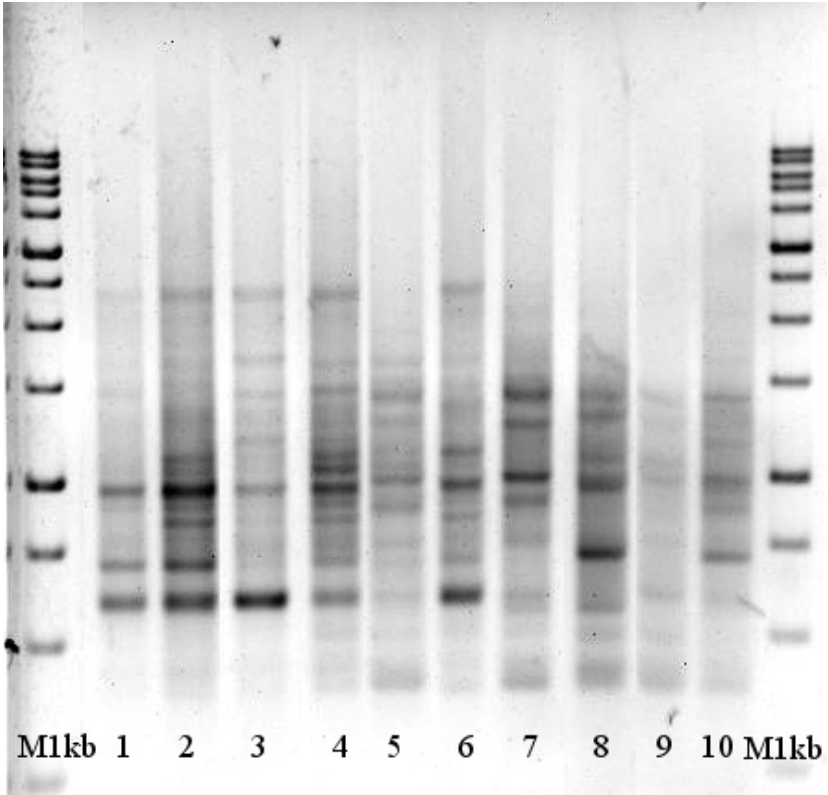

Figure 2. Results of DNA analysis using primer OPB-12 (1,2: location 3 ; 3: location 13; 4: location 14; 5 : location 24; 6,7: location 25; 8: location 29; 9, 10: location 28).

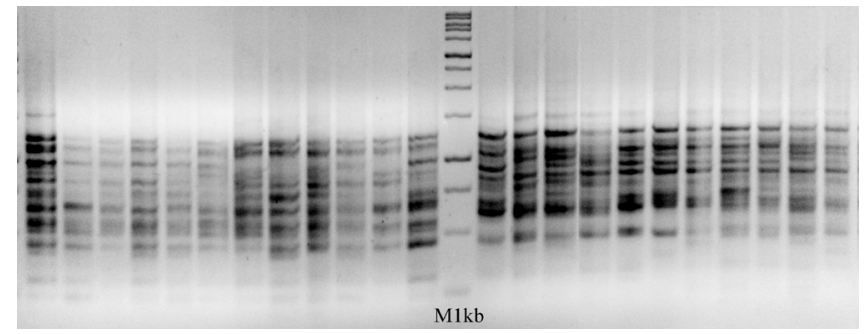

Figure 3. Results of DNA analysis using primer 814 (12 samples from location 29 (I. scariosa) on the left side of the 1-kb DNA marker, and 11 samples from location 6 (I. pumila) on the right side).

\section{References}

Randolph L.F., Mitra J. Karyotypes of Iris species indigenous to the USSR. American J. Botany. 1961;48(10):862-870.

Kryukova A.V., Abramova L.M., Mustafina A.N. To the biology and ecology of rare species of Iris genus in the steppe of South Urals. Samarskaya Luka: Problems Regional Global Ecol. 2018;27(4-1): 271-275.

Makarevitch I., Golovnina K., Scherbik S., Blinov A. Phylogenetic relationships of the Siberian Iris species inferred from noncoding chloroplast DNA sequences. International J. Plant Sci. 2003;164(2): 229-237.

Mikhaylova E.V., Kuluev B.R. Potential for gene flow from genetically modified Brassica napus on the territory of Russia. Environmental Monitoring Assessment. 2018;190:557. DOI 10.1007/s10661-0186946-2.

Acknowledgements. This work was supported by the RFBR grant mol_a 18-34-00022.

Conflict of interest. The authors declare no conflict of interest. 